\title{
Training University Students About Autism Spectrum Disorder Through Outreach to School-Based Speech-Language Pathologists
}

\author{
Joann P. Benigno` \\ Ohio University, benigno@ohio.edu \\ John W. McCarthy \\ Ohio University, mccarthj@ohio.edu \\ Sarah O. Taylor \\ Ohio University, taylors@ohio.edu
}

See next page for additional authors DOI: https://doi.org/10.30707/TLCSD4.1/ZNRR1070

Follow this and additional works at: https://ir.library.illinoisstate.edu/tlcsd

Part of the Scholarship of Teaching and Learning Commons

\section{Recommended Citation}

Benigno', Joann P.; McCarthy, John W.; Taylor, Sarah O.; Hamm, Heather; and Gornichec Wright, Bridget (2020) "Training University Students About Autism Spectrum Disorder Through Outreach to School-Based Speech-Language Pathologists," Teaching and Learning in Communication Sciences \& Disorders: Vol. 4: Iss. 1, Article 4.

DOI: https://doi.org/10.30707/TLCSD4.1/ZNRR1070

Available at: https://ir.library.illinoisstate.edu/tlcsd/vol4/iss1/4

This Scholarly Teaching is brought to you for free and open access by ISU ReD: Research and eData. It has been accepted for inclusion in Teaching and Learning in Communication Sciences \& Disorders by an authorized editor of ISU ReD: Research and eData. For more information, please contact ISUReD@ilstu.edu. 


\title{
Training University Students About Autism Spectrum Disorder Through Outreach to School-Based Speech-Language Pathologists
}

\begin{abstract}
Training preprofessional students about autism spectrum disorder (ASD) is crucial, particularly since students with ASD are represented on the caseloads of approximately $90 \%$ of school-based speechlanguage pathologists (SLPS). When this training can occur within the context of an outreach program, the results of such programming can be mutually beneficial for the individuals served as well as the students. Through the present program, six graduate students and four undergraduate students created materials for 15 SLPs working in the schools in a significantly underserved region of the United States. Students created nearly 800 materials for the SLPs to use in therapy with children with ASD. These included visual schedules and picture/icon cards and social stories. Students completed a survey and wrote a reflection paper about what they learned. Survey data from all participants indicated that the program met the needs of the SLPs and furthered students' skills in creating materials and understanding more about the demands of working as an SLP in the schools. Implications for undergraduate and graduate training including increasing student knowledge and confidence as well as gaining student perspectives on the experience and collaboration are discussed. Future directions for extensions of this training program are proposed.
\end{abstract}

\section{Keywords}

autism spectrum disorder, outreach, speech-language pathologists, students, training

\section{Cover Page Footnote}

This project was funded by the Autism Speaks Local Grants Program. The authors would also like to thank the students and SLPs who participated in this project.

\section{Authors}

Joann P. Benigno', John W. McCarthy, Sarah O. Taylor, Heather Hamm, and Bridget Gornichec Wright 
Approximately $90 \%$ of school-based speech-language pathologists (SLPs) report they regularly provide services to children with autism spectrum disorder (ASD; American Speech-LanguageHearing Association, 2018). Though experience working with children with ASD leads to greater confidence among SLPs, self-assessment of their confidence, skills, and knowledge in working with children who have ASD varies depending on timing of clinical training and coursework in the field (Cascella \& Colella, 2004; Plumb \& Plexico, 2013; Schwartz \& Drager, 2008). Benigno, McCarthy, Taylor, Wright, and Lee (2019) identified that training opportunities such as learning how to make materials that support the communication of children with ASD are one avenue to pursue in the area of skill development for pre-professional students pursuing a career in speechlanguage pathology or related fields (e.g., psychology and music therapy). In addition to supporting children with ASD and advancing university students' knowledge and skills, community outreach efforts have the potential to benefit other stakeholders including families and SLPs. These outreach programs are even more critical for universities located in underserved school districts, where materials and supplies are frequently funded by the SLPs themselves and time to create effective materials is limited by workload and caseload demands.

In rural areas of the country, professionals and family members of individuals with ASD experience a number of barriers to diagnosis and treatment (Antezana, Scarpa, Valdespino, Albright, \& Richey, 2017; Elder, Brasher, \& Alexander, 2016). Limited resources for children with ASD as well as the distance that families are required to travel to receive adequate services are among the challenges reported by individuals in underserved areas. Additionally, families under financial stress face obstacles in finding services for their children. In sum, difficulties accessing services for children with ASD is a significant barrier for families in rural communities. Such barriers as well as lower socioeconomic status and awareness of the diagnostic characteristics of ASD lead families in underserved areas to turn to the schools to provide support for their children (Antezana et al., 2017).

Caseload and workload are frequently reported challenges of school-based SLPs (Harris, Prater, Dyches, \& Heath, 2009; Hutchins, Howard, Prelock, \& Belin, 2010; Katz, Maag, Fallon, Blenkarn, \& Smith, 2010). According to the American Speech-Language-Hearing Association (2018), the median caseload size of school SLPs in Ohio is 55 students, which is higher than the national median caseload of 48 students. Research has shown that once caseloads exceed 40 students, SLPs begin to report that their caseloads are difficult to manage (Katz et al., 2010). High caseloads and workloads limit SLPs' time to research and prepare to implement best practices for their students. Further, higher caseloads and workloads are negatively related to job satisfaction among schoolbased SLPs (Hutchins et al., 2010). Given that the caseloads of school SLPs in our state are high and $90.2 \%$ of school-based SLPs regularly provide services to students with ASD (American Speech-Language-Hearing Association, 2018), it is clear that SLPs could benefit from additional assistance to help manage their workload. One way to do so is through the provision of assistance in the implementation of evidence-based practices for students with ASD, which includes the use of visual aids such as social narratives, video models, and schedules (Wong et al., 2015).

\section{Previous Outreach Programs}

There is an emerging literature focused on cultivating students' development within the context of outreach services. In a different training program, Benigno and colleagues (2019) enrolled a total 
of 19 undergraduate students (majors included communication sciences and disorders, music therapy, and psychology) and eight graduate students in speech-language pathology in a twosemester course sequence on ASD. Both courses focused on ASD and involved learning how to create effective, personalized, evidence-based materials such as visual schedules and social stories for children with ASD and their families. The program was mutually beneficial for the families and the university students who participated. Caregivers rated the quality of the materials created by the university students highly. University students not only learned about the different types of materials, but also had firsthand experience creating a range of supports for the families. In addition, graduate students assumed a mentorship role and supported undergraduates in delivering presentations and creating evidence-based materials for families. Students also reported gaining knowledge of ASD. The development of leadership and communication skills (e.g., planning and problem solving) were also among the benefits mentioned by graduate students (Benigno et al., 2019; Wright et al., 2019).

\section{The Present Study}

The benefits associated with training students through community outreach efforts to families inspired our team to reach even more children with ASD by creating materials for school-based SLPs. Our program had two specific aims: 1) to expand and extend the outreach program to schoolbased SLPs working with children with ASD and 2) to provide training opportunities in ASD for undergraduate students in Communication Sciences and Disorders (CSD) and SLP graduate students.

\section{Method}

Participants. Funding for the program was received from the Autism Speaks Local Grants Program (awarded to the first three authors) and the program took place over the course of two consecutive summer and fall semesters. University student participants included six graduate students in the SLP Master's program and four undergraduate students in CSD. One of the graduate students (fourth author) co-coordinated the project with the primary investigator (PI) and received financial support from the grant. Fifteen SLPs were the beneficiaries of the program and were school-based SLPs working in districts within a one-hour radius of the university. On average, the SLPs had 17 children with ASD on their caseload ( $S D=16.1$; range $=5-65)$; 71\% of students with ASD on their caseload were classified as verbal (range $=20 \%-100 \%$ ) and $27.33 \%$ of the students were classified as nonverbal (range $=0 \%-80 \%$ ). It is important to note that our university is situated in the poorest county in its state and poverty rates for the regions served through this grant ranged from 15.5\%-30.2\% (Ohio Development Services Agency, 2019). Through this program, an estimated total of 260 children with ASD were reached through the services our team provided to the SLPs.

All SLPs represented seven different counties in the southeastern Appalachian region of the state. The majority of SLPs $(n=12)$ who participated received our outreach services during the summer; materials were created by three graduate and three undergraduate students. The remaining SLPs participated during the fall semester; materials were created by three SLP graduate students and one undergraduate student enrolled in a graduate seminar on ASD. The project coordinator continued her duties through the fall term. 


\section{Procedures.}

University Student Training and Outreach. The PI (first author) held weekly meetings with all of the graduate and undergraduate students. Across both semesters, students read and discussed articles and resources on current issues surrounding workload and caseload demands of schoolbased SLPs. The workflow model from Benigno et al. (2019) was adapted to suit the needs of SLPs and the time required to design and create the materials for the SLPs (see Figure 1). Students received feedback on drafts of materials from the PI and clinic supervisor as well as the project coordinator. We did not set a limit on what SLPs could request, as our goal was to create as many materials as they needed to support therapy with children with ASD on their caseload.

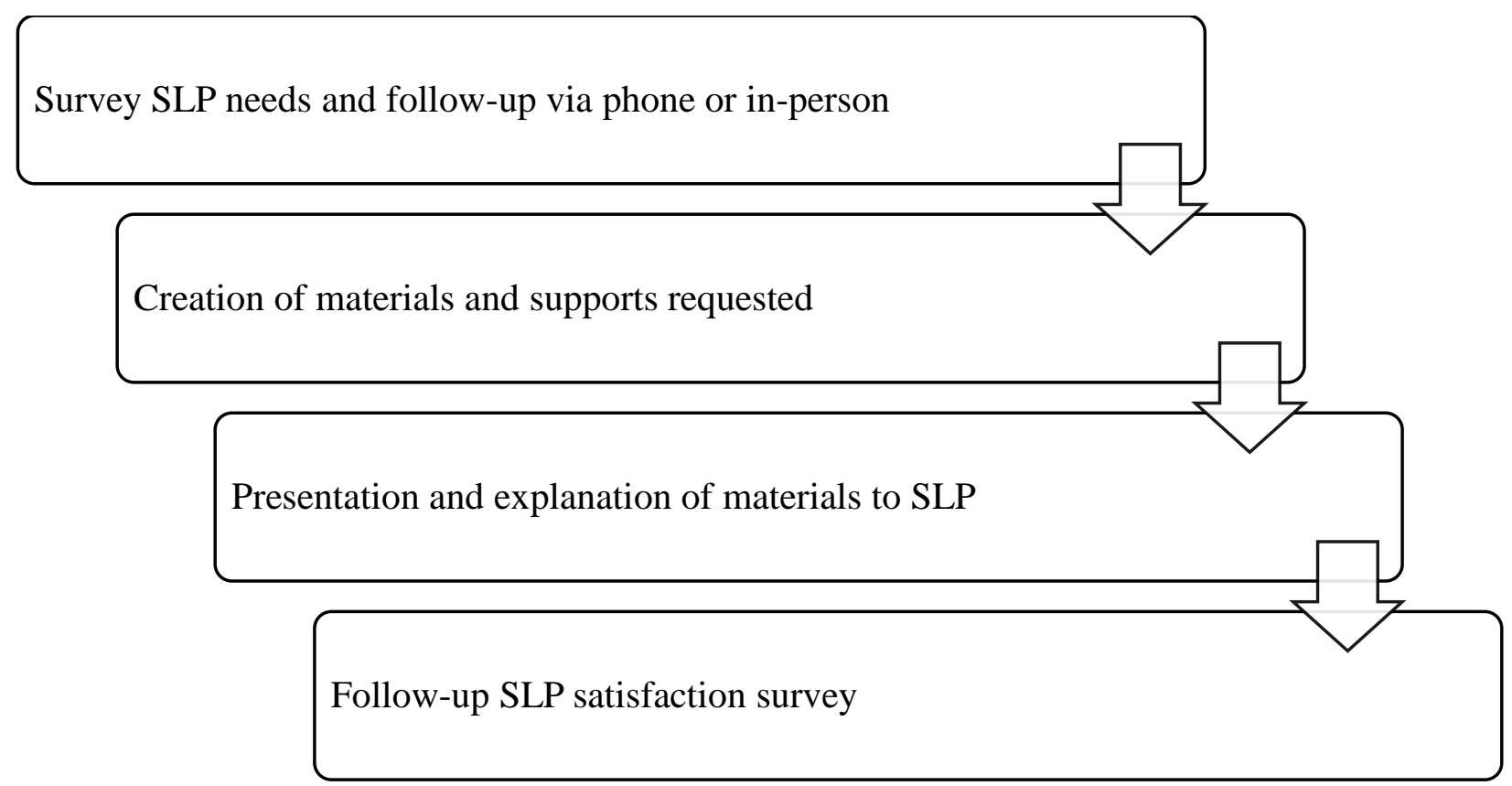

Figure 1. Workflow model for SLP outreach.

Surveys. At the end of the experience, SLPs and students completed a questionnaire that included Likert-type scale items and opportunities to share feedback on their experiences in the program. The SLPs answered 12 Likert scale questions about their satisfaction with their materials and the team, followed by four open-ended questions regarding strengths and weaknesses of the program, suggestions for future iterations of the project, and additional comments. The student follow-up survey included six questions total, inquiring about what students liked most and least about the program, ratings of their knowledge and confidence regarding the types of materials created, and reflections on collaboration with peers. See Appendix for the student follow-up survey.

Student Reflections. Students also wrote a reflection paper about their experiences in the program. They were prompted to address the following in their reflection: skills gained, challenges faced, thoughts on collaboration, and what they learned about during this training experience. 


\section{Results}

A description of materials created by the students and the SLPs' evaluation of the team are described first. Data from the students' surveys and reflection papers follow.

Materials Created by the Students for the Speech-Language Pathologists. On average, each SLP received 53 materials $(S D=22.5$; range $=16-96)$ and a total of 794 materials were created by the students. More than $55 \%$ of materials created were picture cards/icons $(31.1 \%)$ and visual schedules $(24.7 \%)$. The remaining materials were social stories $(14.2 \%)$, choice boards $(10.7 \%)$, and other (19.3\%). Commonly requested types of visual schedules included "If, Then," "My Schedule," and "I am working for..." templates, which SLPs could individualize for each student using the picture icons provided or edit with a dry erase marker. Social stories targeted a wide array of skills, ranging from playing on the playground to initiating conversations. Choice boards requested by SLPs often included two or more boxes where picture icons could be placed to present students with different options for items and activities. Other materials included communication books, icons and sentence strips for adapted books, and sequences for activities of daily living. See Table 1 for an overview of materials created along with examples. In addition to the requested materials reported above, all SLPs received a large bag with additional supplies including items such as folders, dry erase markers and board, velcro, and other adhesive materials. SLPs were also provided with a flash drive containing electronic copies of materials that they could adapt and reproduce for future use.

Table 1

Summary and Examples of Materials Created

\begin{tabular}{|c|c|c|}
\hline Type of material & $\begin{array}{l}\text { Percentage of total } \\
\text { materials }\end{array}$ & Examples \\
\hline Picture cards/icons & $31.1 \%$ & $\begin{array}{l}\text { Bubbles } \\
\text { iPad } \\
\text { Computer } \\
\text { Game } \\
\text { Craft } \\
\text { Clean up }\end{array}$ \\
\hline Visual schedules & $24.7 \%$ & $\begin{array}{l}\text { "I am working for..." } \\
\text { "What I need to do" } \\
\text { Speech schedule checklist }\end{array}$ \\
\hline Social stories & $14.2 \%$ & $\begin{array}{l}\text { Group work/group projects } \\
\text { Taking turns } \\
\text { Staying on topic } \\
\text { Talking to the teacher } \\
\text { Transitioning between activities and settings }\end{array}$ \\
\hline Choice boards & $10.7 \%$ & $\begin{array}{l}\text { Choice between } 2 \text { or more items } \\
\text { "My choices are... I want..." }\end{array}$ \\
\hline
\end{tabular}


Speech-Language Pathologists' Evaluations of the Team. On the follow-up survey, all 15 SLPs rated the characteristics of the team (e.g., professionalism, communication, and creativity) and the materials (e.g., quality and ease of use) as five out of five, indicating high levels of satisfaction. Statements related to these areas included, "Overall, I am satisfied with the team that worked with me" and "The materials provided met my expectations." One SLP commented, "The team went above and beyond to make me feel welcome and comfortable." Eleven of the SLPs participated during the summer, so they had not yet used their materials at the time of the follow-up survey. Of the four SLPs who participated at the beginning of their school year, each reported that the materials were easy to use and that they and their students used them frequently (all items rated five out of five). Additionally, all SLPs reported that they would recommend this program to other SLPs. Several SLPs also provided comments expressing their thanks and gratitude, such as in the following statement: "This is an excellent program and extremely helpful! I'm grateful for all the materials I received!” Qualitative comments from SLPs about the strengths of the program included: the quality, quantity, adaptability, and flexibility of the materials (43.2\%) and the team's professionalism and ability to accommodate the SLPs' needs (45.4\%).

Students' Outcomes and Perspectives. The student survey yielded both quantitative and qualitative results. The quantitative results regarding students' knowledge of and confidence in creating the three main material types is presented first. Qualitative themes for what students liked and disliked about the program as well as their reflections of the collaborative aspect of the experience will follow.

Knowledge and Confidence. Students had the opportunity to create materials for between three to nine SLPs. Student ratings of knowledge and confidence in creating visual schedules, social stories, and 5-point scales ranged from 4.2 and $5.0(1=l o w, 5=h i g h)$. These were also the three materials that students had the most frequent opportunities to create for the SLPs. All students learned how to use software to create picture icons, which according to the data above, comprised nearly a third of the total materials created.

In addition, students made other types of materials based on the requests of the SLPs. Due to the individual differences in SLPs' requests, select students had the opportunity to create materials including, but not limited to: communication books, adaptable books with sentence strips, sentence strip builders, and behavioral maps. See Table 2 for a summary of students' ratings of knowledge and confidence across the main materials that all students had the opportunity to create.

Table 2

Student Ratings of Knowledge and Confidence by Material Type

\begin{tabular}{lll} 
Type of material & $\begin{array}{l}\text { Knowledge rating } \\
M(\mathrm{SD})\end{array}$ & $\begin{array}{l}\text { Confidence rating } \\
M(\mathrm{SD})\end{array}$ \\
\hline Visual schedules & $5.00(0.00)$ & $4.90(0.32)$ \\
Social stories & $4.40(0.70)$ & $4.20(0.80)$ \\
5-point scales & $4.78(0.44)$ & $4.78(0.44)$
\end{tabular}

Note. Students rated knowledge and confidence on a scale of 1 (low) to 5 (high). 
Likes and Dislikes. Qualitative questions on the survey asked students to reflect on what they liked about the outreach experience as well as what they disliked and how the program could be improved. See Tables 3 and 4 for a summary of student responses. Students most frequently shared positive reflections related to learning about the different types of visual supports and creating the materials for the SLPs. For example, one student appreciated the active participation in the training program by stating: "I liked the hands-on experience most. It is one thing to learn about materials/supports in class, but it is much more meaningful to actually create the materials."

Students also expressed positive views about their contribution to local school-based SLPs, reflecting on how they enjoyed supporting the needs of the SLPs and the students on their caseload. One student wrote about how understanding the needs of SLPs would be beneficial to her future career with the statement: "I enjoyed seeing what practicing SLPs would find helpful to have in their room so that I have an idea of what I may need in the future." Another enjoyable feature of the experience mentioned by the students was their ability to learn about and use various types of software and resources to create the materials for SLPs. The opportunity to collaborate with other undergraduate and graduate students through this program was a component that students appreciated as well. Student perspectives on collaboration will be explored more in the next section.

When students were asked to share parts about the program that they disliked, they described challenges related to time and scheduling secondary to clinic, class, and work responsibilities. Students recognized that having a shift schedule and workflow model in place helped them to coordinate and maximize their time with their team. Students also wrote about how they would have liked more extensive experience with making different types of materials and the opportunity to interact with the SLPs who participated in the project. One student noted, "I would have liked to see the SLPs' reaction to the new materials they received." Other related comments pertained to students' desires to create more personalized supports for individual children on the caseloads of the SLPs. The balance of students' comments classified as "other" included comments about challenges related to technology and communicating with other students assigned to their team.

Table 3

Student Perspectives on What They Liked Most About the Program

\begin{tabular}{ll}
\hline Theme & Frequency \\
\hline Learning about and making materials & 14 \\
Helping/supporting needs of SLPs & 9 \\
Using/learning about software and other resources & 4 \\
Collaboration & 3
\end{tabular}

Note. Frequency refers to the number of times the topic was mentioned in the survey responses. 
Table 4

Student Perspectives on What They Liked Least About the Program

\begin{tabular}{ll}
\hline Theme & Frequency \\
\hline Limited opportunity to interact with/create materials & 5 \\
for SLPs & \\
Time/scheduling challenges & 4 \\
Other (e.g., technology, group communication) & 7 \\
\hline
\end{tabular}

Collaboration. On the final portion of the survey, students were asked to reflect on their ability to collaborate with other members of the team. See Table 5 for a summary of student perspectives on collaboration. Comments made by students most frequently focused on how their team worked together. More specifically, students wrote about how their team members helped each other, asked and answered each other's questions, and shared their ideas and perspectives. Students recognized the importance of collaboration during this outreach program to meet the needs of the SLPs, with one student writing, "Some materials were trickier than others [to create], but having multiple people provide their input made the process easier." In describing good team communication, another student recalled, "I felt that we had very open and clear communication during this project." Students acknowledged the important secondary benefits of collaboration, which resulted in the creation of high-quality materials for the SLPs and the students on their caseloads. Other statements regarding the benefits of collaboration included the preparatory nature of the program in giving students the opportunity to experience the collaborative process. Students worked on developing and refining their skill sets in light of successes and challenges they and their team faced during the training experience.

Table 5

Themes for Students' Perspectives on Collaboration

\begin{tabular}{ll}
\hline Theme & Frequency \\
\hline $\begin{array}{l}\text { Working well with the team (helping, asking questions, } \\
\text { sharing ideas/perspectives }\end{array}$ & 6 \\
High-quality materials & 5 \\
Positive reflections on collaboration & 5 \\
Good team communication & \\
\hline Note. Frequency refers to the number of times the topic was mentioned in the survey responses.
\end{tabular}


Student Reflection Papers. In addition to completing the survey, each student also wrote an individual reflection paper at the end of the experience. Papers were coded for major themes. Nearly $43 \%$ of students' reflections focused on learning about and creating evidence-based materials. More than $25 \%$ of students' statements reflected on how participating in this program furthered their understanding of the needs of the SLPs in the area. Other major themes included using software to create materials $(14.3 \%)$ and collaborating with others $(8.6 \%)$. When sharing her thoughts on the skills she gained in creating various evidence-based materials, one student wrote:

One of the skills I gained during this experience was being able to create more general materials that a speech-language pathologist would be able to adapt for each student... we had to create them in the mindset that they would be used by many children with a range of needs.

Another student wrote more specifically about her improved ability to write social stories, sharing that she gained "the ability to write effective social stories for children with autism in a timely manner" and how to "compose a story based on the specific needs of a child." This student then went on to reflect on how this skill would be beneficial to the children on her caseload as a future SLP. In terms of collaboration during the creation of materials, one student wrote:

I love being able to share ideas and work together with people that have an equally strong passion for what we are doing. I think one of the big benefits of working with other people is being able to bounce off each other's ideas and create something much more than what had originally been planned.

The most commonly mentioned area of difficulty in participating in the program concerned logistics in scheduling and workflow. Students reflected on difficulties regarding finding time to work on materials amid other commitments (e.g., jobs). Additionally, a number of students discussed difficulties with managing the workload earlier on in the program before templates for materials were made. Other challenges mentioned included effectively communicating with team members and working with the different organizational styles of other students.

\section{Discussion}

Summary. This outreach program was deemed a success from both the SLPs' and the students' perspectives. All of the SLPs rated the program and the quality of materials highly. Benefits for students included gaining and refining their skills in creating materials for the SLPs and learning how to collaborate with each other. Students appreciated the opportunity to assist the SLPs and walked away with more knowledge and confidence in creating materials for themselves in the future. This experience also allowed them to learn more about the roles, responsibilities, and demands of working in the schools.

Increasing Students' Knowledge and Confidence. Students reported high levels of knowledge and confidence in creating visual supports for students with ASD, which will be invaluable as they continue into graduate school, their clinical experiences, and beyond. Through the outreach program, students not only learned about the evidence-base of visual supports for individuals with ASD and the needs of SLPs in the schools, but also gained hands-on experience in constructing 
such supports. Students also learned to use new software to create the materials and employ their creative side while constructing the materials. Since the vast majority of SLPs provide services to children with ASD, students will likely be able to transfer the knowledge and skills they gained through this program to create supports for future students and clients.

Creating high quality, effective, and adaptable materials poses challenges. Though the majority of materials created by the students were excellent, it is important to note that quality control is necessary. All materials received a final review by the PI and project coordinator; adjustments were made on an as-needed basis. One specific challenge noted by the students was writing social stories. If a topic was particularly challenging, students coordinated their efforts and as a result, created a much stronger story. Consequently, the content and quality of the materials improved as students gained more first-hand experience with writing them.

Students' Perspectives on the Training Program. In order to improve future delivery of the program, it was important for us to gain insight into what students liked most and least about the training experience. Learning about and making materials was what they liked the most. None of the undergraduates at our institution are involved in service delivery, so this experience was a unique opportunity for them to gain insight into the types of materials that benefit children with ASD and other social communication deficits. Though the graduate students had more clinical encounters with children with ASD, they were still learning how to create effective visual supports. All students discussed that they enjoyed creating these materials in order to help the SLPs. The philanthropic aspect of the program was very appealing and motivating for the students.

Similar to other collaborative student training experiences (Benigno et al., 2019; Brown, Benigno, \& Geist, 2018; Wright et al., 2019), one main challenge reported was balancing the responsibilities of the outreach experience with their other obligations such as coursework, jobs, and graduate clinic hours. Some students did note, however, that these difficulties resolved by the end of the experience. It seems that perhaps once the teams of students learned the ways that they work with and communicate with one another most effectively, they were able to become more time-efficient in the construction of the materials. Additionally, the creation of a variety of templates near the beginning of the experience made it easier to make materials more quickly later on. Through their multiple experiences writing social stories, students also likely became more efficient at writing social stories, which also saved time.

Engaging students in outreach efforts builds a foundation and hopefully instills a desire within them to initiate or be part of connecting with others in their community in the future. Part of the training also involved increasing students' awareness of the reality of working as a school-based SLP. By reading articles on caseload and workload demands, students were able to gain a fuller appreciation of the challenges faced by SLPs on a daily basis and this gave greater purpose to the time and energy they expended to create materials for the SLPs. They also learned that creating some of the materials is costly in terms of time as well as supplies needed.

Reflections on Collaboration. Following the experience, students described both positive features and challenges associated with coordinating with their team members. The majority of students' comments addressed essential features of working well with the members of the team. This included helping each other, sharing ideas, and perspectives, and asking questions as they arose. 
Good team communication and the end goal of creating high quality materials that would benefit the SLPs and their students were also addressed.

As is the case with most collaborative endeavors, coordinating schedules and making sure everyone is "on the same page" can sometimes pose challenges. However, workflow models with specific smaller deadlines as well as consistent communication between faculty, staff, and students provide structure and significantly increase likelihood that tasks will be completed on time. Holding dedicated meetings to discuss progress and assigning a smaller group of students (e.g., two or three, depending on number and complexity of materials requested) also facilitates success. Organizational structure and deadlines are particularly necessary when materials are being created for multiple SLPs. Initially, some students may require more scaffolding and assistance when creating materials; however, the direct guidance required may decrease as they gain more experience and confidence in their abilities.

Limitations and Future Directions. Establishing partnerships between universities and schoolbased SLPs that allow for ongoing support would be even more beneficial than outreach at a single time point. Increasing the involvement of more university students is likewise important. Though all students benefited from the experience, one limitation identified by our students was that the graduate student who served as the project coordinator had the opportunity to engage with the majority of SLPs on two occasions: the intake session as well as the in-person session where they received their materials. Possibilities to address this limitation are to allow more students to engage in the in-person sessions or to video record the sessions so students can review the SLPs' requests at intake and their reactions when receiving their materials at the follow up session.

Additional future directions include exploring student training models that support the sustainability of this important outreach program in our underserved region. Another possibility includes extending the outreach to support the creation of materials for other populations such as children with speech sound disorders and other developmental disabilities. Finally, a wider net can also be cast out to other educational and healthcare professionals including but not limited to special education teachers and pediatricians. The addition of an interprofessional component would not only enhance the quality and range of materials provided, but also foster interprofessional engagement of CSD and SLP students with related fields such as teacher and special education, music therapy, and psychology.

Conclusion. Training programs such as these allow students to develop skills that are in accordance with best practices in our field. Training our students to build and share their knowledge and expertise with their greater community increases our ultimate impact. Through our service to 15 SLPs, we potentially benefited 260 students with ASD in our own little corner of the world while simultaneously providing a unique training opportunity to our university students. It is our hope that our program will inspire other university programs to incorporate outreach to support SLPs in their region who are working with children with ASD and other disabilities.

\section{Disclosures}

Funding for this outreach project was provided through the Autism Speaks Local Grants program awarded to the first three authors. The authors do not have any additional financial or nonfinancial disclosures to report. 


\section{References}

American Speech-Language-Hearing Association. (2018). Schools survey. Retrieved from https://www.asha.org/uploadedFiles/Schools-2018-SLP-Caseload-and-WorkloadCharacteristics.pdf

Antezana, L., Scarpa, A., Valdespino, A., Albright, J., \& Richey, J. A. (2017). Rural trends in diagnosis and services for autism spectrum disorder. Frontiers in Psychology, 8, 1-5. doi: https://doi.org/10.3389/fpsyg.2017.00590

Benigno, J. P., McCarthy, J. W., Taylor, S. O., Wright, B. G., \& Lee, C. (2019). Training students through a community outreach program to support families of children with autism spectrum disorder. Teaching and Learning in Communication Sciences and Disorders, 3(1), article 5.

Brown, L. S., Benigno, J. P., \& Geist, K. (2018). Come together: Music therapy and speechlanguage pathology students' perspectives on collaboration during an inclusive camp for children with ASD. Music Therapy Perspectives, 36(1), 17-25. doi: https://doi.org/10.1093/mtp/mix017

Cascella, P. W., \& Colella, C. S. (2004). Knowledge of autism spectrum disorders among Connecticut school speech-language pathologists. Focus on Autism \& Other Developmental Disabilities, 19, 245-252. doi: https://doi.org/10.1177/ 10883576040190040601

Elder, J. H., Brasher, S., \& Alexander, B. (2016). Identifying the barriers to early diagnosis and treatment in underserved individuals with autism spectrum disorders (ASD) and their families: A qualitative study. Issues in Mental Health Nursing, 37, 412-420. doi: https://doi.org/10.3109/01612840.2016.1153174

Harris, S. F., Prater, M. A., Dyches, T. T., \& Heath, M. A. (2009). Job stress of school-based speech-language pathologists. Communication Disorders Quarterly, 30, 103-111. doi: https://doi.org/10.1177/1525740108323856

Hutchins, T. L., Howard, M., Prelock, P. A., \& Belin, G. (2010). Retention of school-based SLPs: Relationships among caseload size, workload satisfaction, job satisfaction, and best practice. Communication Disorders Quarterly, 31, 139-154. doi: https://doi.org/10.1177/1525740109336870

Katz, L. A., Maag, A., Fallon, K. A., Blenkarn, K., \& Smith, M. K. (2010). What makes a caseload (un)manageable? School-based speech-language pathologists speak. Language, Speech, and Hearing Services in Schools, 41, 139-151. doi: https://doi.org/10.1044/01611461(2009/08-0090)

Ohio Development Services Agency. (2019). The Ohio Poverty Report. Retrieved from https://www.development.ohio.gov/files/research/p7005.pdf

Plumb, A. M., \& Plexico, L. W. (2013). Autism spectrum disorders: Experience, training, and confidence levels of school-based speech-language pathologists. Language, Speech, and Hearing Services in Schools, 44(1), 89-104. doi: https://doi.org/10.1044/01611461(2012/11-0105)

Schwartz, H., \& Drager, K. D. R. (2008). Training and knowledge in autism among speechlanguage pathologists: A survey. Language, Speech, and Hearing Services in Schools, 39(1), 66-77. doi: https://doi.org/10.1044/0161-1461(2008/007) 
Wong, C., Odom, S. L., Hume, K. A., Cox, A. W., Fettig, A., Kucharczyk, S., ... \& Schultz, T. R. (2015). Evidence-based practices for children, youth, and young adults with autism spectrum disorder: A comprehensive review. Journal of Autism and Developmental Disorders, 45, 1951-1966. doi: https://doi.org/10.1007/s10803-014-2351-z

Wright, B. M., Kuykendall, K., Apsley, J., McCullough, N., Doerbaum, H., Fowler, M. ...\& Benigno, J. P. (2019). Student reflections on participation in a training and outreach program for families of children with autism spectrum disorder. Teaching and Learning in Communication Sciences and Disorders, 3(1), article 6. 


\section{Appendix}

\section{Autism Speaks Project Survey: Students}

1. Are you a graduate student or undergraduate student?

2. I assisted in the production of materials for Speech-Language Pathologists.

3. Reflect on what you liked most about this experience. List at least 3 specific aspects you enjoyed the most.

4. Reflect on what you liked least about this experience. List at least 3 specific suggestions that we can incorporate in the future.

5. Please rate each material listed on the following parameters: (1) knowledge gained, (2) confidence in applying that knowledge, and (3) opportunities to assist (rate the relative amount of opportunities you had to assist with the production of this particular material type). ( $1=$ low; $5=$ high) Provide specific comments for each type of material.
a. Creating a mini communication book
b. Picture Exchange Communication System
c. Social cartoons and social thinking
d. Social Stories
e. Visual schedules
f. Incredible 5-Point Scale
g. Other (please specify)
h. Other (please specify)

6. Reflect on your ability to collaborate with other members of the team to execute the completion of the materials for the Speech-Language Pathologists. 